\title{
Crafting employee engagement through talent management practices in telecom sector
}

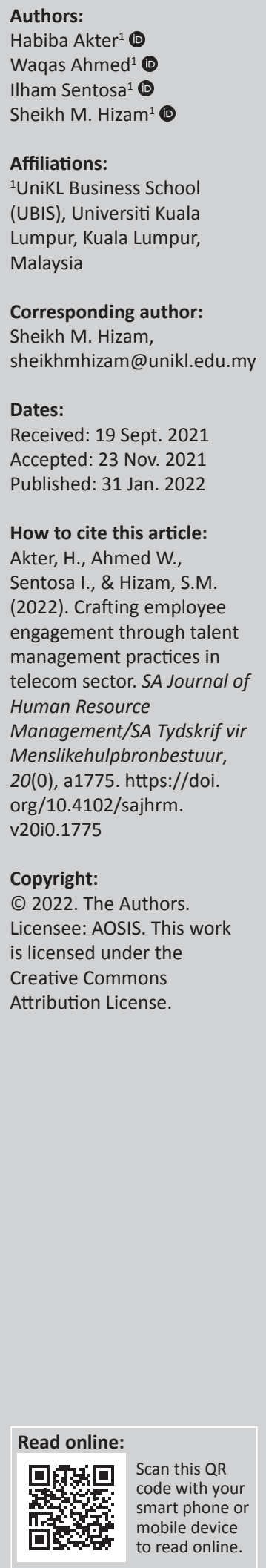

Authors:

Ilham Sentosa ${ }^{1}$ (D)

Affiliations:

${ }^{1}$ UniKL Business Schoo

(UBIS), Universiti Kuala

Lumpur, Kuala Lumpur,

Sheikh M. Hizam,

Dates:

Accepted: 23 Nov. 2021

Published: 31 Jan. 2022

article:

Akter, $\mathrm{H}$, Ahmed W.,

engagement through talent

management practices in

Human Resource

Management/SA Tydskrif vir

Menslikehulpbronbestuur,

org/10.4102/sajhrm.

v20i0.1775

Copyright:

Licensee: AOSIS. This work

is licensed under the

ve commons

mobile device
Orientation: Solving the dearth of skilled employees and maintaining the engagement policy are key concerns of the Malaysian telecom sector. Therefore, talent management practices have created a mainstream process for telecom employers to be proactively involved in talent engagement.

Research purpose: This study aimed to elucidate the vital talent management practices towards employee engagement in telecom sector, incorporating psychological empowerment as a mediator.

Motivation for the study: Studies linking talent management with career development, rewards and recognition, training and development, are still not established in terms of employee engagement in the context of Malaysian telecom sector.

Research design, approach and method: An online survey was conducted through the purposive sampling technique to collect data from telecom firms in Malaysia. The survey resulted in 242 responses, which were analysed through Partial Least Squares - Structural Equation Modelling (PLS-SEM) and PLS-Predict. In PLS-SEM, data were evaluated for hypothesis testing. After hypothesis result was obtained, the PLS-SEM model was assessed for its predictive validity through PLS-Predict.

Main findings: The results explored that talent management factors positively and significantly predicted employee engagement through psychological empowerment, except training and development. The PLS-Predict resulted a higher value of predictive power for our model.

Practical/managerial implications: This study may lead to practical applications to support human resource management practitioners towards comprehending the impact of talent management practices, either directly or indirectly, in engaging the right talent.

Contribution/value-add: This study will fill the untapped area of improving employee engagement by adding psychological empowerment as a mediator between employee engagement and talent management practices.

Keywords: talent management practices; psychological empowerment; employee engagement; telecom sector; social exchange theory; PLS-SEM; PLS-predict.

\section{Introduction}

During the 1970s and 1980s, employees' satisfaction was the key focus area for human resource management (HRM), which had little impact on or no link to organisational productivity. Thereafter, the focus went beyond employee commitment, as commitment is a vital factor predicting engagement (Aktar \& Pangil, 2018).

As a result of increasing global competition in businesses, HRM strategy began to change with HRM leaders effectively balancing both individual and organisational needs. At the end of the 1980s, employees were encouraged to be engaged in their job roles and as well as being focused on their talents to achieve organisational goals. These were the main conceptualization aspects of employee engagement (EE).

Employment engagement emerged for the first time in management theory in 1990. Various scholars have given a different definitions of EE since then; therefore it is sometimes difficult to comprehend the exact meaning of the term 'engagement' . Engagement is often delineated in the management literature as a 'positive, fulfilling, work-related state of mind, which is categorised by vigour, dedication and absorption' (Schaufeli, Salanova, González-Romá, \& Bakker, 2002, p. 74). 
With the advent of EE in the academic domain, many scholars opined that EE is a crucial factor for organisational success. The HR policymakers also affirm that EE initiative improves organisational productivity, enhances customer satisfaction and decreases turnover intention (Aktar \& Pangil, 2018; Sheikh, Christina, \& Sharina, 2020). However, claims have been made repeatedly that nowadays engaged employees are shortening and disengaged workforce is deepening. According to the recent Gallup (2017) survey, 85\% of employees are disengaged throughout the world, resulting in a greater level of financial loss (around \$7 trillion). The survey also reported that only 19\% of staff are engaged throughout the Southeast Asian countries (e.g. Malaysia, Singapore, Thailand, etc.) (Gallup, 2017).

According to the Department of Statistics Malaysia (DOSM), the information and communications technology (ICT) sector is the major contributor to the Malaysian economy, especially the telecom sector with the highest value of gross output and value-added of Malaysian Ringgit (RM)87.4 billion and RM49.5 billion, respectively, (DOSM, 2019a, 2019b). Although $\mathrm{EE}$ is one of the leading contributor to the productivity and effectiveness of the Malaysian telecom sector (Khan \& Bukhari, 2020), the telecommunication companies are facing several challenges to engage and retain the right talent (MCMC, 2015; Sheikh et al., 2020; TalentCrop, 2018).

A recent report revealed that in 2020, the Malaysian ICT sector was confronted with a deficient workforce totalling to 9000 employees. If the employers do not address this issue urgently, the demand for talented employees will increase manifold by 2025 (KKMM, 2018). According to Alias, Nor and Hassan (2016), the Malaysian ICT organisations should focus on strategic initiatives such as talent management practices (TMPs) for not only attracting the right talent but increasing the engagement levels to retain them. Sheikh et al. (2020) also stated that to retain the right talent, telecom professionals in Malaysia should put in more efforts to manage the engagement level.

The talent shortage problem that the Malaysian telecom sector is experiencing has enlarged the skill-gap amongst its employees. The importance of TMP is critical in this aspect. A study evidenced that TMP is imperative for attracting, developing, engaging and maintaining a strong talent pool. The research also found that the term 'talent management (TM)' is broadly practiced in today's business world, however, more studies are required to evaluate the impact of TMP on organisational strategy. Employers therefore, need to reconsider their policies towards TM to improve their EE strategy (Pandita \& Ray, 2018).

Several factors of TM have become crucial for the telecom sector in Malaysia to manage top talent. According to a survey conducted by the Academy of Sciences Malaysia (ASM), 51\% of companies revealed the low-skilled workforce factor as the prominent reason for employee disengagement in the telecom sector, whilst $25 \%$ stated the incapability of meeting employees' expected salary. Thus, training and development
(TD) and rewards and recognition (RR) may be crucial in fostering EE (ASM, 2018). Another survey in the context of Malaysia's Information Technology (IT) and telecom sector found that $57 \%$ of staff are concerned about career development (CD) to be more engaged at the workplace (Cooper, 2015).

Although previous researchers over the past decades have studied the influence of TMP on EE (Alias et al., 2016), there is a paucity of studies that link TM with CD, RR and TD in terms of EE in the Malaysian telecom sector. Some earlier researchers have also suggested psychological empowerment (PE) as an intervening factor between TMP and different outcomes at the individual level (Khan, Yasir, Majid, \& Afridi, 2019). However, this relationship is less comprehensible because of its underlying mechanisms. In this context, the previous studies had undertaken numerous theories such as social exchange theory (SET) to understand the EE mechanism. According to Khoreva and Vaiman (2015), SET posits that when employers give priority to skilled workers to be involved through TMP, they reciprocate by engaging at the organisation.

To explore this addressing gap, our study aims to examine the relevance of TMP (e.g. CD, RR and TD) towards EE based on SET, incorporated in PE as a mediator and empirically test it among the workforces in the telecom sector in Malaysia.

\section{Literature review}

\section{Social exchange theory}

We have focused on the SET developed by Blau (1964), which is relevant for this study. Based on Saks's (2006) opinion, a strong theoretical rationale for explicating EE has been found within SET. According to Khoreva, Vaiman and Zalk (2017), to perceive the effectiveness of TMP, which leads to positive employee behaviour, SET provides a suitable lens for better understanding the scenario. Stein and Min (2019) evidenced that SET directs a positive relation between HRM practices and PE, which leads to employees' positive outcomes. Social exchange theory explains that engagement emerges as the approach of exchanging or 'refunding' the belief that employers 'offer' to their staff (Ugwu et al., 2014). Hence, this study combines TMP and PE with the theory of social exchange to determine their direct or indirect impact on EE.

\section{Connections between talent management practices and employee engagement}

The term 'TMP' covers talent transformation, TD programmes, talent involvement, RR and talent deployment (Pandita \& Ray, 2018). As TMP is closely tied with different facets of HRM, therefore, organisations should consider the significance of TMP whilst planning for EE strategies.

An important factor of TMP goes towards CD to manage the right talent. As defined by Arthur, Hall and Lawrence (1989), $\mathrm{CD}$ is a set of programmes intended to accomplish employees' needs in terms of creating a better career path in the 
organisation. According to Pandita and Ray (2018), when scholastically exploring TM, scholars widen the notion to involve CD strategy in an organisation for a long time. The authors further explained that when employees undergo career advancement programmes, their self-confidence buildup towards their career which stimulates them to be more involved in their work roles. Hence, CD as an effective TM factor has a positive relationship with EE (Alias et al., 2016). Aktar and Pangil (2018) and Anitha (2014) also revealed a positive impact of CD on EE.

Rewards and renumeration as a tool of TMP is also considered as a means for effectively engaging the workforce. In line with Bandura's (1977) concept, reward controls behavioural outcomes outwardly because it leads to future reimbursements to those who deserve it. Whilst recognition, is a significant driver of behaviour beyond any benefits being related to it. These constructs consist of vital TMPincluding compensations, company benefits and location (Tymon, Stumpf, \& Doh, 2010). Rewards and recognition opportunities create employees' positive feelings about their jobs and thereby influence EE. A growing number of researchers have linked RR as an efficient dimension of TMP with individual outcomes. For example, Alias et al. (2016) and Ghosh, Rai, Chauhan, Baranwal and Srivastava (2016) confirmed that RR positively influences EE. Along similar lines, a more recent study found RR has a positive impact on EE (Aktar \& Pangil, 2018).

Training and development is another significant factor of TMP that is to be deliberated in the way of enhancing workforces' engagement. According to Aguinis and Kraiger (2009), training is meant as a systematic way that affects one's knowledge, abilities and behaviours leading to efficiency. On the other hand, development is referred to as a systematic action that influences one's knowledge, abilities and behaviours leading to self-development.

Keeping the ability to learn effectively through TD programmes expands persons' skills and abilities, makes them strongly engaged and highly satisfied at their jobs. They also provide a better scope for self-development (Aguinis \& Kraiger, 2009). Researchers have found that TD is positively and significantly linked to EE (e.g. Aktar \& Pangil, 2018; Presbitero, 2017).

Extending the aforesaid reasoning, we propose the following hypotheses:

H1a: CD positively influences EE.

H2a: RR positively affects EE.

H3a: TD has a positive impact on EE.

\section{Linking talent management practices, psychological empowerment and employee engagement}

Psychological empowerment is reflected on individuals' task orientation within a set of four cognitive factors including: meaning, competence, self-determination and impact (Spreitzer, 1995). In line with Jose and Mampilly's (2014) opinion, PE helps to improve employees' thoughts of meaning, competence self-determination and impact, and therefore higher levels of engagement.

There are several well-established research works which validate that $\mathrm{PE}$ is positively associated with greater engagement levels at the workplace. Nawrin (2016), for instance, explained that psychologically empowered staffs convey the key attributes of engagement on the job and organisational level. More specifically, past researchers found that PE positively and significantly predicted EE (Arefin, Alam, Islam, \& Rahaman, 2019).

Several studies found TMP as the key player to increase PE. Although there are different controversial results, many researchers empirically found that TMP (CD, RR, TD) positively and significantly influence PE (Arefin et al., 2019; Matsuo, 2019; Moradi \& Dashti, 2016). In the direction of mediating effect of PE, the relationship between TMP and employee outcome has been documented in various research works, but contradictory outcomes have been found in the context of relationship amongst these variables. However, PE has a direct or partial or full mediating effect on the relationship between TMP and employee outcome, which has been discoursed in prior studies (Arefin et al., 2019; Khan et al., 2019). Given these shreds of evidence, we hypothesise that:

H1b: $C D$ has a positive effect on PE.

H2b: RR has a positive effect on PE.

H3b: TD is positively connected with PE.

H1c: PE mediates the connection between $\mathrm{CD}$ and EE.

H2c: PE mediates the effect of RR on EE.

H3c: PE plays as a mediator in the connection between TD and EE.

H4: PE is positively linked to EE.

\section{Research framework}

Studying and evaluating the findings from signified literature reviews as detailed above, the authors have proposed the research framework as illustrated in Figure 1. This framework underlines the influence of TMP (e.g. CD, RR, TD) on EE with the existence of PE as a mediator. They propose the hypotheses for TMP factors as: CD with three hypotheses (i.e. H1a for $\mathrm{CD} \rightarrow \mathrm{EE}, \mathrm{H} 1 \mathrm{~b}$ for $\mathrm{CD} \rightarrow \mathrm{PE}, \mathrm{H} 1 \mathrm{c}$ for $\mathrm{CD} \rightarrow \mathrm{PE} \rightarrow \mathrm{EE}$ ), RR also with three hypotheses (i.e. H2a for $\mathrm{RR} \rightarrow \mathrm{EE}, \mathrm{H} 2 \mathrm{~b}$ for $\mathrm{RR} \rightarrow \mathrm{PE}$ and $\mathrm{H} 2 \mathrm{c}$ for $\mathrm{RR} \rightarrow \mathrm{PE} \rightarrow \mathrm{EE}$ ) and TD also showing three paths (i.e. H3a for TD $\rightarrow E E, H 3 b$ for $\mathrm{TD} \rightarrow \mathrm{PE}, \mathrm{H} 3 \mathrm{c}$ for $\mathrm{TD} \rightarrow \mathrm{PE} \rightarrow \mathrm{EE}$ ), whilst $\mathrm{PE}$ has one hypothesis, that is, $\mathrm{H} 4$ for $\mathrm{PE} \rightarrow \mathrm{EE}$.

\section{Research methodology}

To build the methodology base, research onion by Saunders, Lewis and Thornhill (2016) was considered to design philosophy, approach and strategies for this research. The 


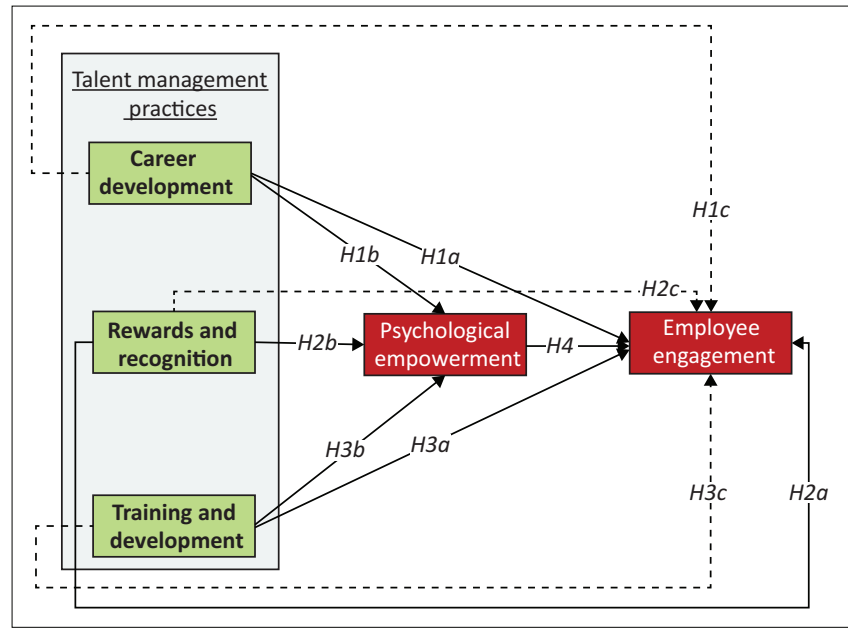

FIGURE 1: Proposed research framework.

positivism philosophy was adopted to choose the research design. In the positivist paradigm, causal research which deals with the cause and effect relationships amongst the variables is undertaken as practiced in this research. For the research approach, we adopted SET from various viewpoints in measuring certain factors, which impact employee behaviour, therefore, the deductive approach was selected for this quantitative research.

\section{Sampling and data collection}

In this study, we carried out an online survey with a crosssectional approach for collecting the primary data. The respondents were chosen from telecom companies in Malaysia. The purposive sampling technique was preferred to reach the respondents who are the best option to collect the required data (Sekaran \& Bougie, 2016). We explained the main objective of the research to the companies' internal team correspondence to obtain permission for the data collection.

The online survey link was sent to the respondents who were employed in different departments such as Administration and customer care, financial and technical. The survey continued for 8 weeks and a total of 242 responses were gathered. The respondents participated anonymously and voluntarily in which they were convinced of the confidentiality of their responses. The minimum sample size for Partial least squares-structural equation modelling (PLSSEM) was projected as per the rule of 5-times the number of measurement items in the proposed model (Hair, Sarstedt, Ringle, \& Mena, 2012). Therefore, 242 collected responses were considered adequate for conducting the PLS-SEM analysis.

\section{Measuring instruments}

This study mainly covers three major constructs including TMP (e.g. CD, RR, TD), PE and EE. We adopted the items for each construct from the validated studies. Career development was measured adopting six items taken from Imandin, Bisschoff and Botha's (2015) study. 05 measurement items for RR were drawn from the Saks's (2006) study. Training and development was measured adapting five items developed by Edgar and Geare (2005). A total of 12 items were derived from Spreitzer's (1995) study for evaluating PE. Employee engagement was assessed using nine items, which are the widely used instruments to measure EE (Schaufeli et al., 2002).

The questionnaire had two sections with demographic particulars of respondents (such as gender, age, qualification, experience, department, etc.) in Part-A and Part-B consisted of variable questions or items. These items were assessed through a 5-point Likert-scale (i.e. $1=$ strongly disagree to $5=$ strongly agree). A total of 37 question items based on the five variables of the proposed model were used to collect the responses for testing the hypotheses.

\section{Data analysis techniques}

The PLS-SEM analysis method was used to analyse study data. In PLS-SEM, data reliability, validity, factor loadings, variance inflation factor (VIF), regression path coefficients and hypothesis testing were employed. Finally, to assess the predictive validity of the PLS-SEM model, we also conducted the PLS-Predict algorithm through two error metrics, that is, mean absolute error (MAE) and root mean square error (RMSE) with the Q-square-root of both PLS and linear regression model (LM). Towards the data analysis, SmartPLS v3.3 was employed.

\section{Results}

\section{Demographic results}

Of the 242 respondents, $61.8 \%$ of the respondents were males whilst females represented $38.2 \%$. A total of $42.7 \%$ of respondents were Chinese, whilst the rest of them were either Malay, Indian or of other nationalities. Based on the education level, about $60 \%$ of the respondents had a bachelor's degree. In the context of job level, the majority of the participants $(74 \%)$ held the position of executive or senior officer level. On the basis of age group, 39.7\% of the participants were from the age group 21-30 years, $44.3 \%$ from 31-40 years, whilst others were from the age group of 41 to 50 years or above 50-years. Also, most of the participants had 1-5 years of job experience at telecom companies. Most of the sample population was employed in the technical department i.e., $38.2 \%$. In terms of renumeration, $39.7 \%$ of the respondents were from the salary bracket of $\mathrm{RM} \leq 3000$, followed by $35.9 \%$ who received RM3001 - RM6000 of the salary and the remaining 24.5\% had been paid either RM6001 - RM9000 or above RM9000 as salary.

\section{Reliability and validity}

Using SmartPLS software 3.3 version, our findings showed that both Cronbach's alpha and composite reliability values of each construct lie between 0.80 and 0.90 , respectively. According to Hair, Babin, Anderson and 
TABLE 1: Reliability, discriminant validity, factor loadings and collinearity statistics.

\begin{tabular}{|c|c|c|c|c|c|c|c|c|c|c|c|}
\hline \multirow[t]{2}{*}{ Variables } & \multirow[t]{2}{*}{ Items } & \multirow[t]{2}{*}{$\alpha$} & \multirow[t]{2}{*}{ CR } & \multirow[t]{2}{*}{ AVE } & \multicolumn{5}{|c|}{ Discriminant validity } & \multirow[t]{2}{*}{ Loadings } & \multirow[t]{2}{*}{ VIF } \\
\hline & & & & & $C D$ & $R R$ & $T D$ & $P E$ & $E E$ & & \\
\hline \multirow[t]{5}{*}{ Career Development (CD) } & CD-1 & 0.887 & 0.914 & 0.641 & - & - & - & - & - & 0.829 & 2.288 \\
\hline & $\mathrm{CD}-2$ & & & & & & & & & 0.867 & 2.820 \\
\hline & $C D-3$ & & & & & & & & & 0.795 & 1.912 \\
\hline & CD-4 & & & & & & & & & 0.805 & 2.188 \\
\hline & $C D-5$ & & & & & & & & & 0.797 & 2.198 \\
\hline \multirow{5}{*}{$\begin{array}{l}\text { Rewards and Recognition } \\
\text { (RR) }\end{array}$} & RR-1 & 0.865 & 0.903 & 0.651 & 0.708 & - & - & - & - & 0.747 & 1.596 \\
\hline & RR-2 & & & & & & & & & 0.868 & 2.362 \\
\hline & RR-3 & & & & & & & & & 0.874 & 2.524 \\
\hline & RR-4 & & & & & & & & & 0.760 & 1.823 \\
\hline & RR-5 & & & & & & & & & 0.774 & 1.788 \\
\hline \multirow{4}{*}{$\begin{array}{l}\text { Training and Development } \\
\text { (TD) }\end{array}$} & TD-1 & 0.899 & 0.926 & 0.714 & 0.768 & 0.626 & - & - & - & 0.862 & 2.820 \\
\hline & TD-2 & & & & & & & & & 0.816 & 2.356 \\
\hline & TD-4 & & & & & & & & & 0.823 & 2.205 \\
\hline & TD-5 & & & & & & & & & 0.820 & 2.330 \\
\hline \multirow{12}{*}{$\begin{array}{l}\text { Psychological } \\
\text { Empowerment (PE) }\end{array}$} & PE-1 & 0.925 & 0.936 & 0.549 & 0.371 & 0.354 & 0.313 & - & - & 0.719 & 2.146 \\
\hline & PE-2 & & & & & & & & & 0.694 & 2.003 \\
\hline & PE-3 & & & & & & & & & 0.769 & 2.327 \\
\hline & PE-4 & & & & & & & & & 0.770 & 2.759 \\
\hline & PE-5 & & & & & & & & & 0.734 & 2.285 \\
\hline & PE-6 & & & & & & & & & 0.742 & 2.243 \\
\hline & PE-7 & & & & & & & & & 0.786 & 2.394 \\
\hline & PE-8 & & & & & & & & & 0.766 & 2.707 \\
\hline & PE-9 & & & & & & & & & 0.735 & 2.282 \\
\hline & PE-10 & & & & & & & & & 0.677 & 1.907 \\
\hline & PE-11 & & & & & & & & & 0.741 & 2.358 \\
\hline & PE-12 & & & & & & & & & 0.752 & 2.425 \\
\hline \multirow{7}{*}{ Employee Engagement (EE) } & $\mathrm{EE}-3$ & & & & & & & & & 0.780 & 2.232 \\
\hline & $\mathrm{EE}-4$ & & & & & & & & & 0.794 & 2.339 \\
\hline & EE-5 & & & & & & & & & 0.820 & 2.764 \\
\hline & $\mathrm{EE}-6$ & & & & & & & & & 0.785 & 2.560 \\
\hline & $\mathrm{EE}-7$ & & & & & & & & & 0.780 & 2.212 \\
\hline & $\mathrm{EE}-8$ & & & & & & & & & 0.781 & 2.560 \\
\hline & EE-9 & & & & & & & & & 0.774 & 2.340 \\
\hline
\end{tabular}

VIF, variance inflation factor; $C R$, composite reliability; AVE, average variance extracted.

Black (2018), Cronbach's alpha and composite reliability values standing between 0.80 and 0.90 are deliberated as highly reliable and acceptable. Therefore, all the constructs in the research model were identified as having a better level of reliability. Furthermore, convergent validity was assessed through average variance extracted (AVE). The AVE values confirmed that all indicators were valid as they exceeded the minimum threshold value of 0.5 (Hair et al., 2018).

Based on the multitrait-multimethod (MTMM) matrix, the heterotrait-monotrait (HTMT) criterion was assessed to establish the discriminant validity of the variables. According to Henseler, Ringle and Sarstedt (2015), if the HTMT ratio is less than 0.85 , it is confirmed that the discriminant validity has been determined by the reflective constructs. In the test of this study, the HTMT approaches reliably detected the discriminant validity between two reflective constructs. Table 1 represents the reliability level and convergent validity level (composite reliability and Cronbach's alpha, AVE) and discriminant validity level (HTMT ratio), respectively, for all the proposed constructs.

\section{Outer loadings}

To measure outer loadings for all the items, we used the SmartPLS. Our results revealed that the outer loadings of the items ranged from 0.70 to 0.90 , which were viewed as appropriate items. Here only CD-6, PE-2 and PE-10 did not found the criteria, whereas the value range for the items was not above 0.70 . As the outer loadings above 0.70 are acceptable levels for analysis, all the indicators of each construct have been reliably preferred for this study. On the other hand, the outer loading values of $0.50-0.60$ are still widely accepted (Soelton et al., 2020). Hence, the items from CD-6, PE-2 and PE-10 were also accepted. The overall outer loadings of each item are shown in Table 1 . The collinearity statistics, that is, VIF for each instrument was also calculated for inner model assessment in SmartPLS and found appropriate (i.e. depicted in Table 1) as a 


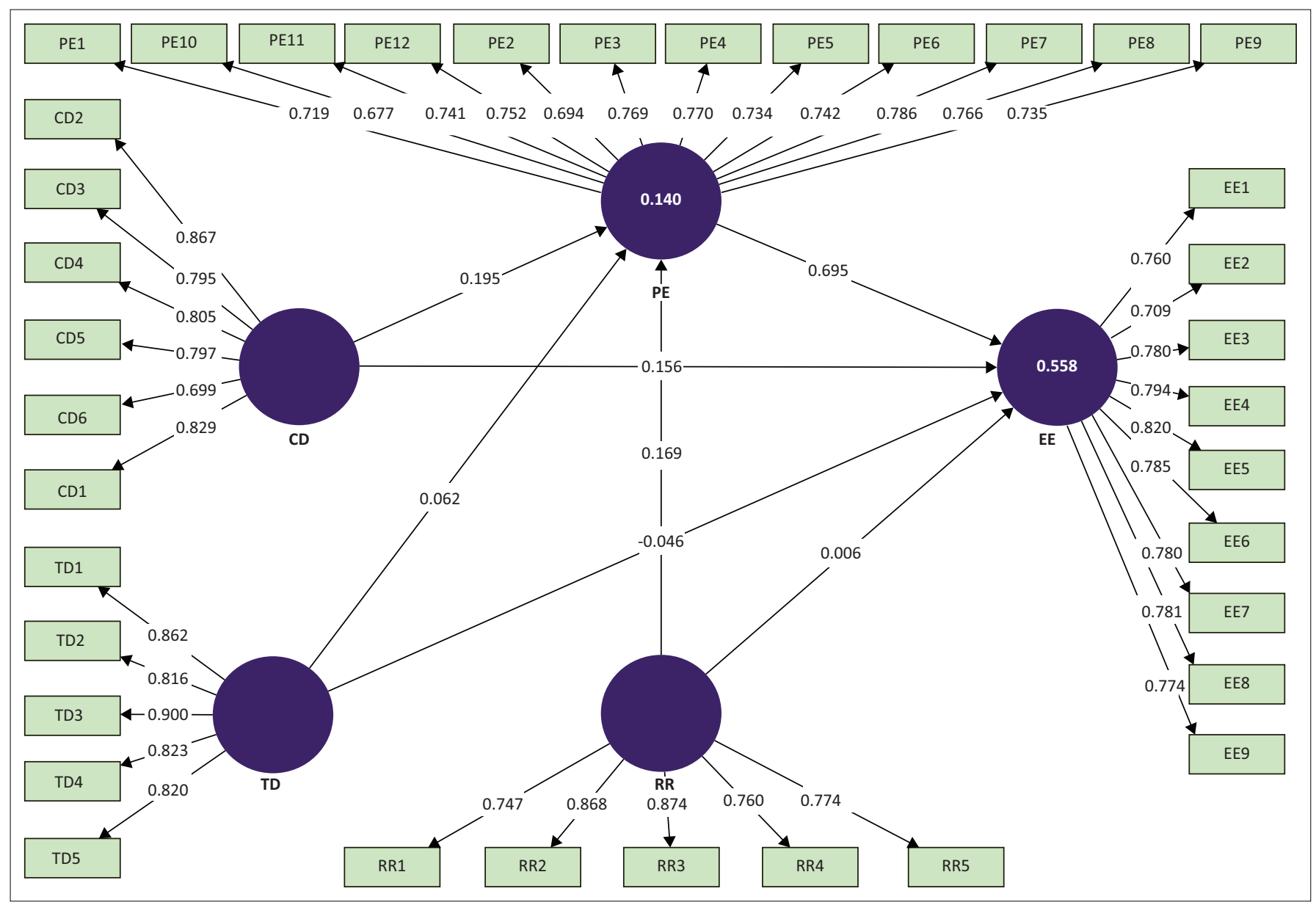

RR, rewards and recognition; TD, Training \& Development; EE, Employee Engagement; PE, Psychological Empowerment; CD, Career Development FIGURE 2: Measurement model from partial least squares-structural equation modelling analysis.

recommended value of $>5$ was achieved (Sarstedt, Ringle, \& Hair, 2017).

\section{Structural model}

The SEM was applied for ensuring the causal relationship amongst TMP (CD, RR, TD), PE and EE. In PLS, $\mathrm{R}^{2}$ is assessed for measuring the effects of latent variables. The analytical findings of PLS-SEM show that the $\mathrm{R}^{2}$ (variance explained)for the endogenous variables $\mathrm{EE}$ and $\mathrm{PE}$ were 0.56 and 0.14 , respectively (see Figure 2). This signifies that CD, RR, TD and $\mathrm{PE}$, could explain $56 \%$ of the variance for EE. the findings also revealed that $14 \%$ of the variance for PE could be explained by $C D, R R$, TD. Table 2 denotes the direct and indirect effects with $R^{2}$ and Adjusted $R^{2}$ in the endogenous variables.

Furthermore, each proposed hypothesis was tested using SEM. Findings from Table 2 show that a significantly positive connection exists between $\mathrm{CD}$ and $\mathrm{EE}(\beta=16 \%, p<0.05)$. Thus, hypothesis H1a was validated.

In addition, based on the prediction in Table 2, a weak positive direct impact of RR on EE has been found, whilst TD negatively influences EE. However, these findings are not statistically significant $(p>0.05)$. Hence, hypotheses $\mathrm{H} 2 \mathrm{a}$ and $\mathrm{H} 3 \mathrm{a}$ are not supported. On the other hand, CD and RR are positively and significantly associated with PE $(p<0.05)$, supporting hypotheses $\mathrm{H} 1 \mathrm{~b}$ and $\mathrm{H} 2 \mathrm{~b}$. Our findings also confirm that TD positively but not significantly impact PE. Therefore, hypothesis $\mathrm{H} 3 \mathrm{~b}$ is not confirmed. Interestingly, the PE is found to be a strong predictor of $\mathrm{EE} \mathrm{(} \beta=70 \%, p<$ 0.001). Thus, H4 is robustly accepted. To determine the mediation, it has already been found that the indirect effect of CD and RR are significant $(p<0.05)$, whilst TD has an insignificant effect $(p>0.05)$. These findings support hypotheses $\mathrm{H} 1 \mathrm{c}$ and $\mathrm{H} 2 \mathrm{c}$, but do not confirm hypothesis $\mathrm{H} 3 \mathrm{c}$. The overall significance level for each hypothesis is indicated in Figure 3.

\section{Partial least squares-predict}

Towards an assessment of predictive validity of the proposed framework, the novel method of PLS-Predict was utilised. This PLS-predict algorithm adopted from Shmueli, Ray, Velasquez Estrada and Chatla (2016), assessed the predictive ability and concentrated on the overfitting problems by generating the holdout samples to execute the crossvalidation. Guidelines to evaluate the predictive power of framework were adopted from García-Fernández, MarteloLandroguez, Vélez-Colon and Cepeda-Carrión (2018) Hair (2021) Hair et al. (2020) Shmueli et al. (2019). To measure the predictive validity of endogenous variables (PE and EE), two 
TABLE 2: Results of hypothesis testing with $R^{2}$ and adjusted $R^{2}$

\begin{tabular}{|c|c|c|c|c|c|c|c|}
\hline Hypotheses & Path & Path coefficient & $T$ statistics & $p$ & Results & R-square & Adjusted $\mathrm{R}^{2}$ \\
\hline $\mathrm{H} 1 \mathrm{a}$ & $\mathrm{CD} \rightarrow \mathrm{EE}$ & 0.156 & 2.070 & 0.039 & Accepted & $E E=0.558$ & $E E=0.551$ \\
\hline $\mathrm{H} 2 \mathrm{a}$ & $\mathrm{RR} \rightarrow \mathrm{EE}$ & 0.006 & 0.102 & 0.919 & Rejected & & \\
\hline H3а & $\mathrm{TD} \rightarrow \mathrm{EE}$ & -0.046 & 0.658 & 0.511 & Rejected & & \\
\hline $\mathrm{H} 1 \mathrm{~b}$ & $\mathrm{CD} \rightarrow \mathrm{PE}$ & 0.195 & 2.198 & 0.028 & Accepted & $P E=0.140$ & $P E=0.129$ \\
\hline $\mathrm{H} 2 \mathrm{~b}$ & $\mathrm{RR} \rightarrow \mathrm{PE}$ & 0.169 & 2.060 & 0.040 & Accepted & & \\
\hline $\mathrm{H} 3 \mathrm{~b}$ & $\mathrm{TD} \rightarrow \mathrm{PE}$ & 0.062 & 0.707 & 0.480 & Rejected & & \\
\hline $\mathrm{H} 4$ & $\mathrm{PE} \rightarrow \mathrm{EE}$ & 0.695 & 11.669 & 0.000 & Accepted & - & - \\
\hline $\mathrm{H} 1 \mathrm{c}$ & $\mathrm{CD} \rightarrow \mathrm{PE} \rightarrow \mathrm{EE}$ & 0.136 & 2.106 & 0.036 & Accepted & - & - \\
\hline $\mathrm{H} 2 \mathrm{c}$ & $\mathrm{RR} \rightarrow \mathrm{PE} \rightarrow \mathrm{EE}$ & 0.118 & 2.047 & 0.041 & Accepted & - & - \\
\hline $\mathrm{H} 3 \mathrm{c}$ & $\mathrm{TD} \rightarrow \mathrm{PE} \rightarrow \mathrm{EE}$ & 0.043 & 0.698 & 0.485 & Rejected & - & - \\
\hline
\end{tabular}

$\mathrm{RR}$, rewards and recognition; $T D$, training and development; $\mathrm{EE}$, employee engagement; $\mathrm{PE}$, psychological empowerment; $\mathrm{CD}$, career development.

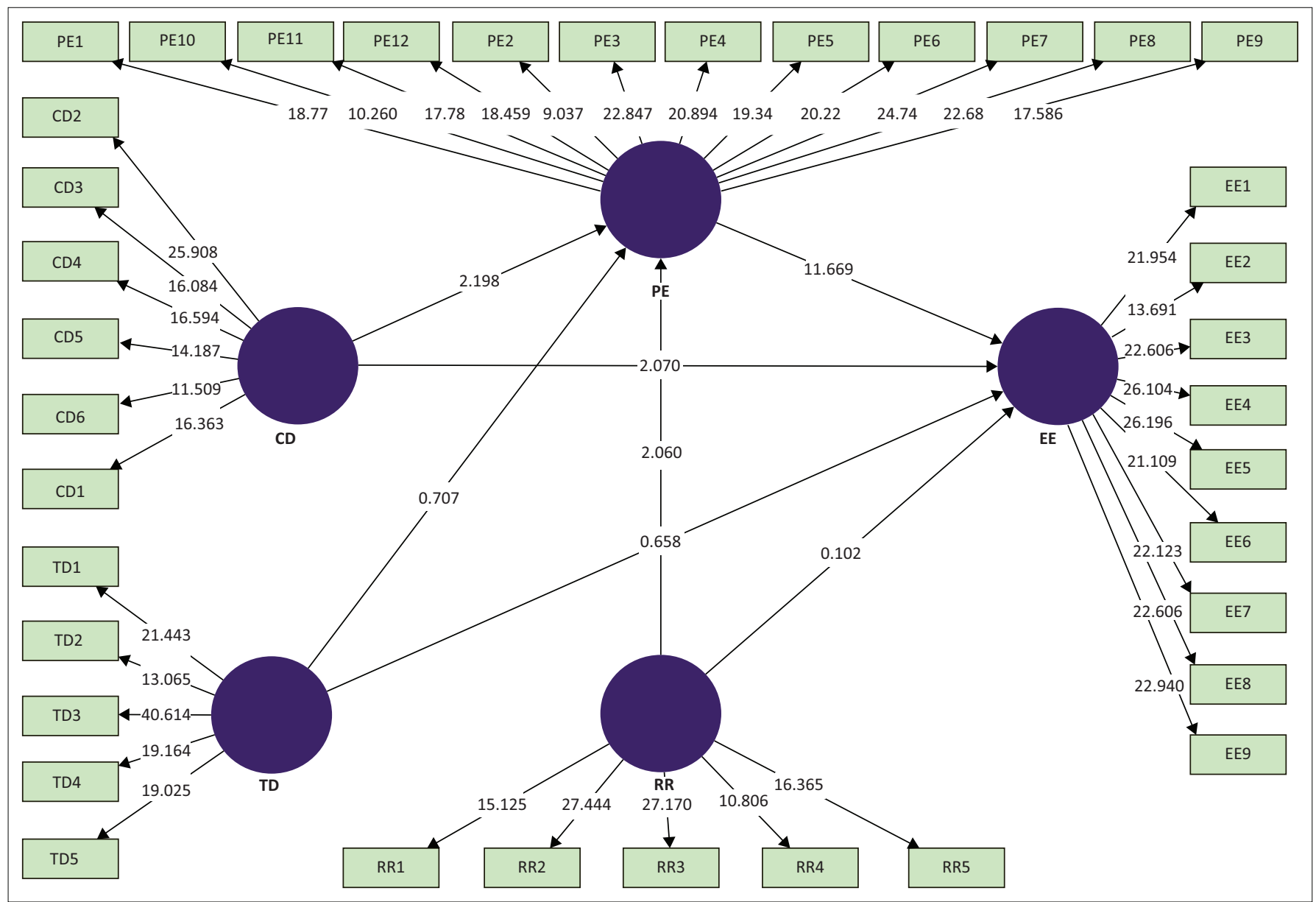

$R R$, rewards and recognition; TD, training and development; $E E$, employee engagement; $P E$, psychological empowerment; $C D$, career development.

FIGURE 3: Structural model from PLS-SEM analysis.

error metrics, that is, MAE and RMSE were considered. By applying the PLS-predict algorithm to whole data, the predictive validity of the model was assessed through error metrics and $Q$ square root $\left(Q^{2}\right)$. It can be seen from Table 3 that RMSE and MAE values in the PLS section are lower than multiple linear (ML) (i.e. multiple linear regression) sections whilst $Q^{2}$ values are greater than ML's respective values, which indicates quite a higher predictive power of our proposed model with non-overfitting problems (Kasilingam \& Krishna, 2021). Moreover, the positive Q2 values of endogenous variables (i.e. $\mathrm{EE}=0.105$ and $\mathrm{PE}=0.093$ ) confirm the predictive relevance of our model. The PLS-predict for the model fulfilled the required criteria as depicted in Table 3.

\section{Discussions and practical implications}

The objective of this study was to investigate the TMP for predicting engagement levels amongst telecom employees by assessing the mediation effect of PE. In our study, TMP comprises three factors, namely $\mathrm{CD}, \mathrm{RR}$ and TD. Our findings confirmed that $C D$ had a significantly positive connection on $\mathrm{EE}(\beta=16 \%, p<0.05)$. Thus, hypothesis H1a $(\mathrm{CD} \rightarrow \mathrm{EE})$ was supported. This outcome is aligned with earlier researchers' findings (Alias et al., 2016; Anitha, 2014). Our findings also indicated that RR positively but not significantly forecasted EE. Besides, a negative and 
TABLE 3: Partial least squares-predict.

\begin{tabular}{|c|c|c|c|c|c|c|c|c|c|}
\hline \multirow[t]{2}{*}{ Items } & \multicolumn{3}{|c|}{ PLS } & \multicolumn{3}{|c|}{ LM } & \multicolumn{3}{|c|}{ PLS-LM } \\
\hline & RMSE & MAE & $Q^{2}$ & RMSE & MAE & $Q^{2}$ & RMSE & MAE & $Q^{2}$ \\
\hline EE1 & 0.721 & 0.496 & 0.042 & 0.758 & 0.532 & -0.06 & -0.037 & -0.036 & 0.102 \\
\hline EE2 & 0.753 & 0.534 & 0.062 & 0.783 & 0.585 & -0.013 & -0.03 & -0.051 & 0.075 \\
\hline EE3 & 0.72 & 0.528 & 0.079 & 0.746 & 0.565 & 0.01 & -0.026 & -0.037 & 0.069 \\
\hline EE4 & 0.759 & 0.571 & 0.049 & 0.799 & 0.604 & -0.053 & -0.04 & -0.033 & 0.102 \\
\hline EE5 & 0.763 & 0.523 & 0.091 & 0.793 & 0.573 & 0.016 & -0.03 & -0.05 & 0.075 \\
\hline EE6 & 0.779 & 0.53 & 0.075 & 0.824 & 0.579 & -0.035 & -0.045 & -0.049 & 0.11 \\
\hline EE7 & 0.812 & 0.57 & 0.059 & 0.829 & 0.611 & 0.02 & -0.017 & -0.041 & 0.039 \\
\hline EE8 & 0.824 & 0.578 & 0.024 & 0.845 & 0.612 & -0.025 & -0.021 & -0.034 & 0.049 \\
\hline EE9 & 0.818 & 0.59 & 0.085 & 0.857 & 0.631 & -0.005 & -0.039 & -0.041 & 0.09 \\
\hline PE1 & 0.801 & 0.572 & 0.031 & 0.841 & 0.615 & -0.066 & -0.04 & -0.043 & 0.097 \\
\hline PE2 & 0.795 & 0.574 & 0.076 & 0.819 & 0.586 & 0.018 & -0.024 & -0.012 & 0.058 \\
\hline PE3 & 0.741 & 0.519 & 0.086 & 0.778 & 0.563 & -0.01 & -0.037 & -0.044 & 0.096 \\
\hline PE4 & 0.822 & 0.579 & 0.087 & 0.861 & 0.625 & -0.001 & -0.039 & -0.046 & 0.088 \\
\hline PE6 & 0.815 & 0.601 & 0.063 & 0.852 & 0.646 & -0.025 & -0.037 & -0.045 & 0.088 \\
\hline PE7 & 0.767 & 0.543 & 0.051 & 0.792 & 0.587 & -0.011 & -0.025 & -0.044 & 0.062 \\
\hline PE8 & 0.794 & 0.557 & 0.018 & 0.811 & 0.597 & -0.024 & -0.017 & -0.04 & 0.042 \\
\hline PE9 & 0.751 & 0.533 & 0.034 & 0.781 & 0.572 & -0.044 & -0.03 & -0.039 & 0.078 \\
\hline PE10 & 0.765 & 0.539 & 0.016 & 0.798 & 0.579 & -0.072 & -0.033 & -0.04 & 0.088 \\
\hline PE11 & 0.777 & 0.594 & 0.042 & 0.807 & 0.618 & -0.033 & -0.03 & -0.024 & 0.075 \\
\hline PE12 & 0.799 & 0.583 & 0.05 & 0.846 & 0.618 & -0.065 & -0.047 & -0.035 & 0.115 \\
\hline
\end{tabular}

$\mathrm{RR}$, rewards and recognition; TD, training and development; $\mathrm{EE}$, employee engagement; $\mathrm{PE}$, psychological empowerment; $\mathrm{CD}$, career development;RMSE, root means squares error; MAE, mean absolute error; PLS-LM, partial least squares-linear regression model.

insignificant connection between TD and EE was found. Therefore, hypotheses H2a (RR $\rightarrow \mathrm{EE})$ and H3a (TD $\rightarrow \mathrm{EE})$ were not supported. This statement does not concur with results received in previous studies that RR and TD have a positive effect on EE (Aktar \& Pangil, 2018; Alias et al., 2016). Besides, all the three factors of TMP (i.e. CD, RR and TD) positively influenced PE. For example, $C D$ and RR were positively and significantly associated with PE $(\beta=0.20$ and 0.17 , respectively), whilst TD had a positive but insignificant impact $(\beta=0.06)$. Hence, hypotheses $\mathrm{H} 1 \mathrm{~b}(\mathrm{CD} \rightarrow \mathrm{PE})$ and $\mathrm{H} 2 \mathrm{~b}$ $(\mathrm{RR} \rightarrow \mathrm{PE})$ were supported, whilst hypothesis $\mathrm{H} 3 \mathrm{~b}(\mathrm{TD} \rightarrow \mathrm{PE})$ was not supported. Similar findings were confirmed by earlier researches also (Arefin et al., 2019; Matsuo, 2019; Moradi \& Dashti, 2016). Also, the result confirmed that PE changed a greater level of EE $(\beta=0.70$ and $p<0.001)$. This evidence strongly supported hypothesis $\mathrm{H} 4$ (PE $\rightarrow E E)$. Such an outcome coincides with prior researchers' findings (Arefin et al., 2019; Nawrin, 2016).

As per the desirable mediation analysis, the findings of this study showed that EE was not robustly affected by the proposed factors of TMP. The role of PE in mediation practice had a stronger effect on the connection between TMP and EE. For example, this study's findings revealed that $\mathrm{CD} \rightarrow \mathrm{PE} \rightarrow \mathrm{EE}$ : $(\beta=0.14, p<0.05), \mathrm{RR} \rightarrow \mathrm{PE} \rightarrow \mathrm{EE}:(\beta=0.12, p<0.05), \mathrm{TD} \rightarrow \mathrm{PE} \rightarrow$ EE: $(\beta=0.04, p>0.05)$. These findings confirmed the indirect effect of all the variables except TD. Our results are consistent with prior evidence that the effect of TMP via PE has a solid understanding of employee outcomes in the Malaysian telecom sector (Khan et al., 2019). This is the novelty of our study because of the paucity of researches in terms of the intervening role of PE on the relationship between TMP and EE. According to Pandita and Ray (2018), high-skilled employees tend to engage more in organisational excellence than low-skilled ones. But, only TMP cannot strongly predict EE. The mediating role of PE would be to reinforce the relationship between the two variables. However, our results have proved that TMP positively affects employees' positive behavioural outcomes through PE. According to Pandita and Ray (2018), productivity in an organisation is the function of EE and employees' work satisfaction as well, which can be brought about by an efficient TM strategy via PE (Arefin et al., 2019; Khan et al., 2019). Hence, this study will enable HRM leaders to choose the TMP to engage potential employees through PE.

Precisely, as predictive validity of our model also proved the PLS-Predict, model findings ensured that all the factors in the proposed model have resulted in $56 \%$ of change towards EE. The results are consistent with SET that signifies a viable theoretical model. Saks (2006) unveiled that SET explains the reciprocal actions between two persons create an obligation in the stage of mutual interconnection. According to Khoreva et al. (2017), TMP delivers a suitable lens for highly skilled workforces to respond positively. Hence, TMP requires to be combined with SET for a better understanding of the scenario. On the other hand, SET directs a positive association between TMP and PE, which leads to productive employee outcomes (Stein \& Min, 2019). Similarly, a strong connection between PE and EE has been found within SET (Kosar, 2017). This theory has provided essential support to develop and test the proposed research model with mediation effects. However, drawing on SET, our findings mainly highlight the importance of TMP to influence EE, either directly or indirectly.

This research contributes to the existing literature by examining the mediation role of $\mathrm{PE}$ in the relationship 
between TMP and EE. Past literature has mostly focused on the connection between either employees' innovative work behaviour (Khan et al., 2019), organisational citizenship behaviour (Arefin, Arif, \& Raquib, 2015) or knowledge sharing intention (Han, Seo, Li, \& Yoon, 2016). With this study's contribution, telecommunications managers may therefore focus on PE as a potential meditator to understand their employees' positive intentions to work. As this study has empirically evidenced that TMP can positively affect employees' intention to engage in the work environment via $\mathrm{PE}$, this would benefit telecommunications companies to recognise the link between TMP and PE to ensure EE. Particularly, we suggest that PE could be a strong intermediate factor to strengthen the effect of TMP on EE. This form of internal link amongst TMP, PE and EE may be considered a reliable form to gain a competitive advantage.

The findings of this research also support several interesting practical implications. Firstly, this study would benefit telecommunications leaders and HRM practitioners to understand the link between TMP and EE, which in turn will diminish turnover intentions. According to Wang, $\mathrm{Xu}$, Zhang and Li (2020), studies on EE have become a conduit to guide academics, HR practitioners and organisations to understand behavioural expectations of the right talent towards the current retention policy. Secondly, as engagement occurs at each level in an organisation, strategic planning on enhancing engagement in the workplace may lead to long-term benefits. In such a way, workers may desire to put effort into their job responsibilities that refer to meaningfulness, determination and connection (SHRM, 2016).

The telecom sector is categorised as a highly growing market in the tech-business world, thus, maintaining proper staff settings is an essential concern that may result in sustainable business development. In this respect, through fulfilling the employees' needs, for example, giving career opportunities and providing TD programmes to work in the organisation, telecom employers may sense the positive employee outcomes, that is, high levels of EE and commitment.

On another note, this research would be crucial to provide a detailed strategic plan of looking at EE in the hybrid workplace context. For instance, although most employers put effort into the process of digitalisation, not every employer has kept up successfully with organisations shaping digitally (Attaran, Attaran, \& Kirkland, 2019), whilst $75 \%$ are still struggling on EE as reported in Social Chorus's survey (Brook, 2019). As most organisations have kept EE as one of their top priorities enabling a technology-driven workplace, it is critical that they know what the employees really desire (Buchanan, Kelley, \& Hatch, 2016). Within this context, TMP still remains a focal point in the current HR policy, such that to improve employees' digital competency, proper TD programmes have become indispensable (Attaran et al., 2019). Besides, wherever the workplace remains either traditional or digital, every worker desires an attractive compensation and benefits package (Vulpen, 2020) and, particularly a great career path (Buchanan et al., 2016). As these are the basic needs of an employee therefore organisations and HR practitioners should prudently leverage these facts, which ultimately may drive high EE.

According to Osman, Noordin and Daud (2018), when employees leave the current organisation, their experiences, knowledge and skills that have already been gained will transfer to the new organisation. This is a critical issue in talent mobility. The employers may contemplate the inferences of this study for workforces, which in return boost the sense of inspiration amongst employees and exert an obligation to involve them in work roles with their best effort. Maintaining this reciprocal relationship with employees may integrate inflow of the right talent and increase EE to latch turnover intentions.

Finally, results in this study may lead to strategically enhancing the engagement levels amongst employees. Based on Cropanzano and Mitchell's (2005) opinion, employers should comprehend that engagement is a long-term and ongoing process that involves continual connections to employees' feelings and obligations and a state of mutual relationship. Therefore, this study may facilitate HRM practitioners in maintaining a strong engagement strategy in an organisation by understanding the connection between TM factors and PE by which employees can be willing to involve with their tasks, share their views and contribute to the organisations' success. Henceforth, in order to augment employee productivity, employers should ponder TM strategies and empowerment initiatives in the business landscapes.

\section{Limitations and recommendations}

This section paves some limitations of the research and covers the recommendations for further researcher/s. Firstly, the purposive sampling technique may lead to possible biases, in which, the participants may have responded more accurately than their exact feelings. Secondly, we drew relatively small sample sizes from the Malaysian telecom companies, which were not robustly significant to evaluate the influence of each of the factors on EE. Thus, a larger sample size covering different telecom companies could lead to a greater positive generalisation of the results. Furthermore, the response rates in the survey of managerial employees were relatively low because of the time constraints and the limited interaction with employees amidst COVID-19 pandemic restrictions. More representation of managerial employees in the sample could highlight whether TMP affects the management levels in boosting their engagement levels, vis-à-vis their other counterparts.

A longitudinal approach instead of a cross-sectional study might provide more robust findings. Hence, further longitudinal studies need to be conducted, which may result in stronger findings. In addition, as TMP might have influenced ratings on employees' behavioural outcomes (Pandita \& Ray, 2018), further study can repeat our research 
in other settings for enhancing the generalisability of the findings. Moreover, few researches have particularly shown the intervening effect of PE on the link between TMP and EE. Therefore, further research is needed to strengthen this relationship, which in result may explore additional viewpoints to forecast EE. Lastly, we integrated only three factors, that is, CD, RR and TD with TMP predicting EE. However, digital competency and workforce agility are important aspects of TMP that can greatly affect employees' engagement levels. Thus, future researchers can turn their attention to these two phenomena in terms of EE.

\section{Conclusion}

Employee engagement has been a challenging issue for an organisation since the 1990s, and many studies have shed light on this issue. Following the empirical analysis, our study's findings ensured that only PE can measure its mostly respective relationship. On the other side, our findings also proved that although CD had a significantly positive association with EE, the other proposed factors of TMP (i.e. RR and TD) did not adequately discourse to boost EE. The reason behind this phenomenon is that when employees generally do not perceive RR and TD as a booster in workplace morale. In addition, TD did not significantly affect PE. The reason is that if employees are not satisfied with the TD programmes, their empowerment behaviour would be declined. To determine the mediation, PE should be prudently studied; the result from our study did not support the hypothesised mediating relationship of $\mathrm{H} 3 \mathrm{c}$ (TD $\rightarrow \mathrm{PE} \rightarrow \mathrm{EE})$. Overall, this study empirically validated the research framework and confirmed that more than $50 \%$ of the hypotheses were significantly supported. This statistical evidence confirms that TMP factors do significantly enhance employee engagement, either directly or indirectly. To summarise, these results may support both practitioners and HRM leaders to comprehend what stimulates workers to commit in their workplace and know the link of efficient TM strategies on PE to engage them.

\section{Acknowledgements}

The authors are very thankful to all the participants of their survey, who were drawn from Malaysian telecom companies, for giving their valuable time and effort to fill up the questionnaire form. The authors would also like to thank them for providing noteworthy feedback.

\section{Competing interests}

The authors have declared that no competing interests exist.

\section{Authors' contributions}

H.A. constructed the manuscript and gathered the data. On the other hand, W.A. managed the data analysis. Lastly, I.S. and S.M.H. supervised consolidating this article for publication.

\section{Ethical considerations}

This article followed all ethical standards for research without direct contact with human or animal subjects.

\section{Funding information}

This research did not receive any specific grant from any funding agency in the public, commercial, or not-for-profit sectors.

\section{Data availability}

Data are available from the authors on request.

\section{Disclaimer}

The views and opinions expressed in this article are of the authors and do not necessarily reflect the official policy or position of any affiliated agency of the authors, and the publisher.

\section{References}

Aguinis, H., \& Kraiger, K. (2009). Benefits of training and development for individuals and teams, organizations, and society. Annual Review of Psychology, 60(1), 451474. https://doi.org/10.1146/annurev.psych.60.110707.163505

Aktar, A., \& Pangil, F. (2018). Mediating role of organizational commitment in the relationship between human resource management practices and employee engagement: Does black box stage exist? International Journal of Sociology and Social Policy, 38(7-8), 606-636. https://doi.org/10.1108/IJSSP-08-2017-0097

Alias, N.E., Nor, N.M., \& Hassan, R. (2016). The relationships between talent management practices, employee engagement, and employee retention in the information and technology (IT) organizations in Selangor. In International conference on business management (pp. 101-115). Springer. Retrieved from conference on business management (pp. /doi.org/10.1007/978-981-287-426-9_9

Anitha, J. (2014). Determinants of employee engagement and their impact on employee performance. International Journal of Productivity and Performance Management, 63(3), 308-323. https://doi.org/10.1108/IJPPM-01-2013-0008

Arefin, M.S., Alam, M.S., Islam, M.R., \& Rahaman, M. (2019). High-performance work systems and job engagement: The mediating role of psychological empowerment. Cogent Business and Management, 6(1), 1-17. https://doi.org/10.1080/2331197 5.2019.1664204

Arefin, M.S., Arif, I., \& Raquib, M. (2015). The mediating role of psychological empowerment in the relationship between high-performance work systems and organizational citizenship behavior. European Scientific Journal, 11(2), 264-277.

Arthur, M.B., Hall, D.T., \& Lawrence, B.S. (1989). Generating new directions in career theory: The case for a transdisciplinary approach. In M.B. Arthur, D.T. Hall, \& B.S. Lawrence (Eds.), Handbook of career theory (pp. 7-25). New York, NY: Cambridge University Press.

ASM. (2018). Science outlook 2017. Retrieved from https://issuu.com/asmpub/docs/ so2017

Attaran, M., Attaran, S., \& Kirkland, D. (2019). The need for digital workplace: Increasing workforce productivity in the information age. International Journal of Enterprise Information Systems, 15(1), 1-23. https://doi.org/10.4018/ IJEIS.2019010101

Bandura, A. (1977). Self-efficacy: Toward a unifying theory of behavioral change. Psychological Review, 84(2), 191-215. https://doi.org/10.1037/0033295X.84.2.191

Blau, P.M. (1964). Justice in social exchange. Sociological Inquiry, 34(2), 193-206. https://doi.org/10.1111/j.1475-682X.1964.tb00583.x

Brook, J. (2019). SocialChorus' 2019 internal communicator index. Retrieved from https:// socialchorus.com/ebooks/socialchorus-2019-internal-communicator-index/

Buchanan, J., Kelley, B., \& Hatch, A. (2016). Digital workplace and culture How digital technologies are changing the workforce and how enterprises can adapt and evolve. Retrieved from https://www2.deloitte.com/

Cooper, P. (2015). 2015 employee intentions report Malaysia. Malaysia. Retrieved from http://www.michaelpage.com.sg/sites/michaelpage.com.sg/files/2015 SGMP_EMPLOYEE_INTENTIONS_FINAL_0.pdf

Cropanzano, R., \& Mitchell, M.S. (2005). Social exchange theory: An Interdisciplinary review. Journal of Management, 31(6), 874-900. https://doi. org/10.1177/0149206305279602

DOSM. (2019a). Information and communication technology satellite account 2018. Retrieved from https://www.dosm.gov.my/v1/index.php? $\mathrm{r}=$ column/ 2018. Retrieved from https://wWw.dosm.gov.my/v1/index.php? $\mathrm{r}=$ column/
cthemeByCat\&cat=319\&bul id=UWpOUFBQSjk2TDhJNXFWUFhJZHNEUTO9\&m cthemeByCat $\&$ cat $=319 \&$ bul_id $=$ UW
enu_id=TE5CRUZCblh4ZTZMODZZIbmk2aWRRQT09 
DOSM. (2019b). Information and communications services expanded by 7.8 per cent in value of gross output of RM144.8 billion in 2017. Retrieved from https://www.

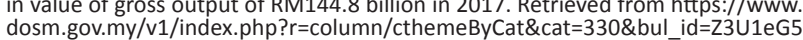
dosm.gov.my/v1/index.php?r=column/cthemeByCat\&cat=330\&bul id=Z3U1eG5
WYzhSZTJ6eWcONXRHUHN1UT09\&menu_id=b0pIV1E3RW40VWRTUKkZocEhyZ1p LUT09

Edgar, F., \& Geare, A. (2005). HRM practice and employee attitudes: Different measures - Different results. Personnel Review, 34(5), 534-549. https://doi. org/10.1108/00483480510612503

Gallup. (2017). State of the global workplace. New York, NY. Retrieved from https:// www.gallup.com/workplace/257552/state-global-workplace-2017.aspx

García-Fernández, J., Martelo-Landroguez, S., Vélez-Colon, L., \& Cepeda-Carrión, G. (2018). An explanatory and predictive PLS-SEM approach to the relationship between organizational culture,organizational performance and customer loyalty: The case of health clubs. Journal of Hospitality and Tourism Technology, 9(3), 438-454. https://doi.org/10.1108/JHTT-09-2017-0100

Ghosh, P., Rai, A., Chauhan, R., Baranwal, G., \& Srivastava, D. (2016). Rewards and recognition to engage private bank employees: Exploring the 'obligation dimension'. Management Research Review, 39(12), 1-16. https://doi. org/10.1108/MRR-09-2015-0219

Hair, J.F. (2021). Next-generation prediction metrics for composite-based PLS-SEM Industrial Management and Data Systems, 121(1), 5-11. https://doi.org/10.1108/ IMDS-08-2020-0505

Hair, J.F., Astrachan, C.B., Moisescu, O.I., Radomir, L., Sarstedt, M., Vaithilingam, S., \& Ringle, C.M. (2020). Executing and interpreting applications of PLS-SEM: Updates for family business researchers. Journal of Family Business Strategy, 12(3), 100392. https://doi.org/10.1016/j.jfbs.2020.100392

Hair, J.F, Babin, B.J., Anderson, R.E., \& Black, W.C. (2018). Multivariate data analysis (8th ed.). India: Cengage.

Hair, J.F., Sarstedt, M., Ringle, C.M., \& Mena, J.A. (2012). An assessment of the use of partial least squares structural equation modeling in marketing research. Journal
of the Academy of Marketing Science, 40, 414-433. https://doi.org/10.1007/ of the Academy of

Han, S.H., Seo, G., Li, J., \& Yoon, S.W. (2016). The mediating effect of organizational commitment and employee empowerment: How transformational leadership impacts employee knowledge sharing intention. Human Resource Development International, 19(2), 98-115. https://doi.org/10.1080/13678868.2015.1099357

Henseler, J., Ringle, C.M., \& Sarstedt, M. (2015). A new criterion for assessing discriminant validity in variance-based structural equation modeling. Journal of the Academy of Marketing Science, 43(1), 115-135. https://doi.org/10.1007/ s11747-014-0403-8

Imandin, L., Bisschoff, C.A., \& Botha, C.J. (2015). Measuring employee engagement of South African managers. Journal of Psychology, 6(2), 110-124. https://doi.org/10 .1080/09764224.2015.11885529

Jose, G., \& Mampilly, S.R. (2014). Psychological empowerment as a predictor of employee engagement : An empirical attestation. Global Business Review, 15(1) 93-104. https://doi.org/10.1177/0972150913515589

Kasilingam, D., \& Krishna, R. (2021). Understanding the adoption and willingness to pay for internet of things services. International Journal of Consumer Studies. https://doi.org/10.1111/ijcs.12648

Khan, A., \& Bukhari, I. (2020). Impact of job autonomy \& employee engagement on organizational effectiveness study on telecommunication sector of Malaysia. International Journal of Research and Analytical Reviews, 7(2), 160-166.

Khan, Z.A., Yasir, M., Majid, A., \& Afridi, S.A. (2019). Talent management practices psychological empowerment and innovative work behavior: Moderating role of knowledge sharing. Clity University Research Journal, 9(3), 567-585.

Khoreva, V., \& Vaiman, V. (2015). Intent vs. Action: Talented employees and leadership development. Personnel Review, 44(2), 200-216. https://doi.org/10.1108/PR-10development

Khoreva, V., Vaiman, V., \& Zalk, M. Van. (2017). Talent management practice effectiveness: Investigating employee perspective. Employee Relations, 39(1) 19-33. https://doi.org/10.1108/ER-01-2016-0005

KKMM. (2018). Communications and multimedia blueprint 2018-2025. Putrajaya.

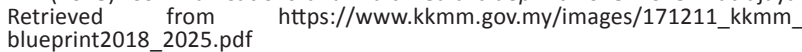

Kosar, R. (2017). The Impact of Psychological Empowerment on Organizational Citizenship Behavior and Knowledge Sharing Behavior: The Mediating role of Employee Engagement and Moderating role of Leader-member exchange. Jinnah Business Review, 5(2), 1-12.

Matsuo, M. (2019). Personal growth initiative as a predictor of psychological empowerment: The mediating role of job crafting. Human Resource Development Quarterly, 30(3), 343-360. https://doi.org/10.1002/hrdq.21347

MCMC. (2015). Talent gap Study for the communications sector in Malaysia. Retrieved from https://www.mcmc.gov.my/skmmgovmy/media/General/pdf/ TalentGAPStudy.pdf
Moradi, F., \& Dashti, N.S. (2016). The impact of human resource practices on psychological empowerment. Management Science Letters, 6, 455-460. https:// doi.org/10.5267/j.msl.2016.6.003

Nawrin, R. (2016). Impact of psychological empowerment on employees' work and organization engagement: A study in the manufacturing sectors, Bangladesh. Mediterranean Journal of Social Sciences, 7(5), 389-395. https://doi.org/10.5901/ mjss.2016.v7n5p389

Osman, I., Noordin, F., \& Daud, N. (2018). Individual entrepreneurial orientation and talent retention of engineers: A pilot survey. In proceedings of the 2nd advances in business research international conference (pp. 11-22). Retrieved from https:// doi.org/10.1007/978-981-10-6053-3_2

Pandita, D., \& Ray, S. (2018). Talent management and employee engagement - A meta-analysis of their impact on talent retention. Industrial and Commercial Training, 50(4), 185-199. https://doi.org/10.1108/ICT-09-2017-0073

Presbitero, A. (2017). How do changes in human resource management practices influence employee engagement? A longitudinal study in a hotel chain in the Philippines. Journal of Human Resources in Hospitality and Tourism, 16(1), 56-70. https://doi.org/10.1080/15332845.2016.1202061

Saks, A.M. (2006). Antecedents and consequence of work engagement. Journal of Managerial Psychology, 21(7), 600-619. https://doi.org/10.1108/02683940610 690169

Sarstedt, M., Ringle, C.M., \& Hair, J.F. (2017). Partial least squares structural equation modeling. In C. Homburg, M. Klarmann, \& A. Vomberg (Eds.), Handbook of market research (pp. 1-40). Springer International Publishing AG. Retrieved from https:// doi.org/10.1007/978-3-319-05542-8_15-1

Saunders, M.N.K., Lewis, P., \& Thornhill, A. (2019). Research methods for business students (8th ed.). London: Pearson.

Schaufeli, W.B., Salanova, M., Gonzalez-Roma, V., \& Bakker, A.B. (2002). The measurement of engagement and burnout: $A$ two sample confirmatory factor analytic approach. Journal of Happiness Studies, 3(1), 71-92. https://doi. org/10.1023/A:1015630930326

Sekaran, U., \& Bougie, R. (2016). Research methods For business: A skill building approach (7th ed.). New York, NY: Wiley.

Sheikh, M.H.S.K., Christina, T.L.C., \& Sharina, O. (2020). The mediating effects of job satisfaction on the relationship between competency mapping, employee engagement, and talent retention: An examination of talent generation $Y$ in Malaysian TELCOs. Talent Development \& Excellence, 12(3), 2357-2371.

Shmueli, G., Ray, S., Velasquez Estrada, J.M., \& Chatla, S.B. (2016). The elephant in the room: Predictive performance of PLS models. Journal of Business Research, 69(10), 4552-4564. https://doi.org/10.1016/j.jbusres.2016.03.049

Shmueli, G., Sarstedt, M., Hair, J.F., Cheah, J.H., Ting, H., Vaithilingam, S., \& Ringle, C.M. (2019). Predictive model assessment in PLS-SEM: Guidelines for using PLSpredict. European Journal of Marketing, 53(11), 2322-2347. https://doi. org/10.1108/EJM-02-2019-0189

SHRM. (2016). Employee job satisfaction and engagement: Revitalizing a changing workforce. Retrieved from http://community.shrm.org/home

Soelton, M., Noermijati, N., Rohman, F., Mugiono, M., Aulia, I.N., \& Siregar, R.E. (2020). Reawakening perceived person organization fit and perceived person job fit: Removing obstacles organizational commitment. Management Science Letters, 10, 2993-3002. https://doi.org/10.5267/j.msl.2020.5.026

Spreitzer, G.M. (1995). Psychological empowerment in the workplace: Dimensions, measurement, and validation. The Academy of Management Journal, 38(5), 1442-1465. https://doi.org/10.2307/256865

Stein, A.M., \& Min, Y.A. (2019). The dynamic interaction between high-commitment HRM and servant leadership: A social exchange perspective. Management Research Review, 42(10), 1169-1186. https://doi.org/10.1108/MRR-02-20180083

TalentCrop. (2018). The pilot critical occupations list report 2015/2016. Retrieved from https://www.talentcorp.com.my

Tymon, W.G., Stumpf, S.A., \& Doh, J.P. (2010). Exploring talent management in India: The neglected role of intrinsic rewards. Journal of World Business, 45(2), 109-121. https://doi.org/10.1016/j.jwb.2009.09.016

Ugwu, F.O., Onyishi, I.E., \& Rodrıguez-Sanchez, A.M. (2014). Linking organizational trust with employee engagement: The role of psychological empowerment. Personnel Review, 43(3), 377-400. https://doi.org/10.1108/PR-11-2012-0198

Vulpen, E.V. (2020). A full guide to compensation and benefits. Retrieved from https:// www.digitalhrtech.com/compensation-and-benefits/

Wang, C., Xu, J., Zhang, T.C., \& Li, Q.M. (2020). Effects of professional identity on turnover intention in China's hotel employees: The mediating role of employee engagement and job satisfaction. Journal of Hospitality and Tourism Management, 45, 10-22. https://doi.org/10.1016/j.jhtm.2020.07.002 